\title{
Psychometric Properties of Emotional Self-Efficacy Questionnaire: \\ Relationships between Emotional Self-Efficacy and Risky Sexual Behaviors
}

Iranian Evolutionary and Educational

Psychology Journal

December 2020: 309-315

(C) University of Hormozgan Publication 2020

DOI: 10.29252/ieepj.2.4.309

http://ieepj.hormozgan.ac.ir

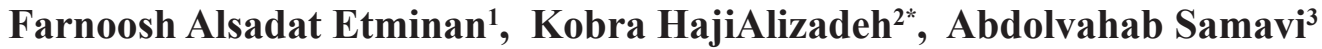

\begin{abstract}
Risky sexual behaviors are associated with a wide range of the physical and social health problems in young people. The role of emotional self-efficacy in preventing risky sexual behaviors is important. The aim of this study was to investigate the psychometric properties of the Emotional Self-Efficacy Questionnaire. In addition, this study examined the relationships between the emotional self-efficacy and risky sexual behaviors. The statistical population of the study included all male and female undergraduate students of Islamic Azad University, Bandar Abbas Branch, Iran. In total, 270 students were selected by stratified random sampling. The final analysis was performed on 260 questionnaires. The research method was descriptive and correlational. Data were collected using two questionnaires of emotional self-efficacy and risky sexual behaviors. Results indicated that the emotional self-efficacy questionnaire has good validity and reliability for implementation on the Iranian sample. The results also revealed a negative and significant relationship (-0.79) between the emotional self-efficacy and high-risk sexual behaviors ( $p<0.05)$. The findings support the role of emotional self-efficacy in preventing risky sexual behaviors.
\end{abstract}

Keywords: Emotional self-efficacy questionnaire, validity, reliability, risky sexual behaviors

\section{Introduction}

Quality of life is one of the most fundamental concepts in positivist psychology (Lopez \& Snyder, 2003). It refers to aspects of life that make life pleasant and valuable (Post, 2014). The domain of quality of life goes beyond the usual symptoms and includes mental well-being, personal satisfaction, functions and shortcomings (Post, 2014). The concept of quality of life is currently used as a sensitive individual and social concept to reflect a sense of respect and attention to humanity from a human perspective (Lavdaniti \& Tsitsis, 2015). On the other hand, one of the variables related to quality of life is emotional self-efficacy. Recent advances in health psychology, mental health, and behavioral medicine have addressed the role of emotional self-efficacy in human health and disease (Han et al., 2005). Just as self-efficacy is an important predictor of performance in a particular area, so can emotional self-efficacy be a good predictor of emotional performance (Loeb, Stempel, \& Isaksson, 2016). Emotional self-efficacy is a set of behavioral preparations and desires of the individual in recognizing, processing and organizing emotional information (Dacre Pool \& Qualter, 2013).

The construct of "self-efficacy" refers to people's belief in their ability to perform and behave successfully to

1. PhD Student of General Psychology, Department of Psychology, Bandar Abbas Branch, Islamic Azad University, Bandar Abbas, Iran

2. Associate Professor, Department of Psychology, Bandar Abbas Branch, Islamic Azad University, Bandar Abbas, Iran

*Corresponding author email: ph_alizadeh@yahoo.com

3. Department of Educational Sciences, Faculty of Humanities Sciences, University of Hormozgan, Bandar Abbas, Iran 
produce the desired result and achievement (Maddux \& Gosselin, 2012). Just as self-efficacy is an important predictor of performance in a particular area, so can "emotional self-efficacy" be a good predictor of emotional performance. Emotional self-efficacy affects the main emotional processes as well as the consequences associated with adaptive and maladaptive emotional functions (Kirk, Schutte, \& Hine, 2008). One of the terms used to describe emotional functions is "emotional intelligence". The four-dimensional model of emotional intelligence states that emotional intelligence encompasses four unrelated functions (Mérida-López \& Extremera, 2017). Emotional self-efficacy is the set of behavioral readiness and desires of the individual in recognizing, processing and organizing emotional information (Valois, Umstattd, Zullig, \& Paxton, 2008). Emotional self-efficacy is rooted in theories of Thorndike (1920) and Gardner (1983). One of the challenges facing the structure of emotional self-efficacy is how to measure it. Previous studies with adults have shown the Emotional Self-Efficacy Scale has good psychometric properties (Pool \& Qualter, 2012). Existing measures of Emotional Self-Efficacy for children and adolescents is related to the management of emotions (Bandura, Caprara, Barbaranelli, Gerbino, \& Pastorelli, 2003). Kirk et al. (2008) contended that ESE should not be limited to just emotion managing and, instead, should map onto a number of various skills in the emotional area as outlined by well established models of emotional functioning. Based on this reasoning, (Kirk et al., 2008) established and validated the ESES, which is based on the fourbranch model of ability emotional intelligence (Mayer \& Salovey, 1997) and encloses questions that refer to to selfefficacy in relation to the ability to recognize, use, appreciate, and manage emotions.

Since there is no suitable tool for measuring self-efficacy in children, adolescents and students to be implemented in Iranian culture, in the present study, the emotional self-efficacy scale of Qualter et al. (2015) was translated for the first time in Iran and its psychometric properties were examined. On the other hand, studies have shown that emotional self-efficacy is one of the factors associated with high-risk sexual behaviors. Studies have shown that high-risk sexual behaviors increase with decreased emotional self-efficacy ((Valois, Zullig, Kammermann, \& Kershner, 2013; Zullig, Teoli, \& Valois, 2014). Several studies found protecting effects of self-efficacy to negotiate safer sex (Sionéan et al., 2002), resist peer force to have sex (DiIorio, Dudley, Soet, \& McCarty, 2004), postponement beginning of sexual intercourse (Santelli et al., 2004), avoid risky sexual behavior (Faryna \& Morales, 2000), and to persist to risky sexual intercourse (Collazo, 2005).

High-risk sexual behaviors are one of the most important public health issues in Iran. Many factors have raised concerns about this issue. These factors can include ethical issues surrounding having sex outside of marriage, and adolescents' lack of psychological maturity to face the consequences of sexual intimacy. High-risk sexual behavior in adolescents is associated with an increased risk of sexually transmitted diseases, AIDS, and unwanted pregnancies (Alimoradi, Kariman, Simbar, \& Ahmadi, 2017). High-risk sexual behaviors include behaviors in which a person engages in sexual behavior without conventional care or engages in multiple sexual partners that can harm both the individual and the community (Ferguson, 2011). Accordingly, the second aim of the present study was to investigate the relationship between emotional self-efficacy and high-risk sexual behaviors in a sample of students. 


\section{Material and Method}

The research method is descriptive and correlational. The statistical population of the present study included all male and female undergraduate students of Islamic Azad University, Bandar Abbas Branch, Bandar Abbas, Iran, who were studying in the academic year of 201-2019. 260 people were selected as the sample size. Of the 260 respondents, 119 (45.8\%) were male and 141 (54.2\%) were female. The instruments of the present study are: Rrisky Sexual Behavior questionnaire designed by Zarie, Khakbaz, and Karami (2010). This questionnaire has 10 items. The scoring of the first eight questions is direct and from 1 to 5 and the last two questions are inverse and vary from 1 to 4, which in total determines the score of high-risk behaviors, so that the higher the score of the person, the more His high-risk behaviors. In Zarie et al. (2010) research, the test-retest reliability of the questionnaire was 0.68 and its Cronbach's alpha was 0.86 . The Emotional Self-Efficacy Scale (ESES) (Qualter et al., 2015) was used to measure emotional self-efficacy. This questionnaire has 27 questions. The Likert response rate is a five-point scale that scores from Agree (1) to Agree (5). For each person, the highest score (160) indicates high emotional self-efficacy and the lowest score (32) indicates low emotional self-efficacy. This scale has 4 subscales (1) use and management of emotions (2) identification and awareness of emotions (3) interaction of emotions with others (4) understanding emotions through face and body language. The factor structure of the questionnaire has been approved and reliability coefficients of the subscales has been reported between 0.69 and 0.88 (Qualter et al., 2015). It should be noted that this questionnaire was translated into Persian for the first time in the present study and psychometric indices were examined.Statistical analysis was performed in SPSS version 21 and AMOS, version 23.

\section{Results}

Kolmogorov-Smirnov test was used to test the hypothesis of normality of the variables. The results showed that the distribution of emotional self-efficacy scores and high-risk sexual behaviors was normal. Confirmatory factor analysis method was used to evaluate the validity of the emotional self-efficacy scale. As shown in Tables 1 and 2, all items have a factor load greater than 0.4. Also, model fit indices were estimated at a satisfactory level.

Table 1. Fitness indicators of the CFA of the emotional self-efficacy scale

\begin{tabular}{|c|c|c|c|c|c|c|c|}
\hline Indices & $\mathrm{P}$ & CMIN/DF & GFI & IFI & TLI & CFI & RMSEA \\
\hline Present research & 0.41 & 2.78 & 0.918 & 0.937 & 0.943 & 0.921 & 0.059 \\
\hline Standard value & $>0.05$ & $<3$ & $>0.90$ & $>0.90$ & $>0.90$ & $>0.90$ & $<0.08$ \\
\hline Fitness status & Good & Good & Good & Good & Good & Good & Good \\
\hline
\end{tabular}


Table 2. Standardized Factor Loadings for the Four-Factor CFA Model of the Emotional Self-Efficacy Scale

\begin{tabular}{|c|c|}
\hline Factor loading & Factor and items \\
\hline \multicolumn{2}{|r|}{ Factor 1: Using and managing your own emotions } \\
\hline 0.59 & 8. I know how to make myself feel better when I am in a bad mood \\
\hline 0.53 & 3. When I feel unhappy, I know how to make myself happy again \\
\hline 0.71 & 18. I know how to use good mood to come up with new ideas \\
\hline 0.62 & $\begin{array}{l}\text { 14. If needed, I know how to change my mood to match the occasion, e.g. make myself feel happy } \\
\text { or sad. }\end{array}$ \\
\hline 0.60 & 12. I know how to control my feelings when I am stressed \\
\hline 0.61 & 22. I know how to make myself feel calm and focused when needed at school \\
\hline 0.52 & 20. I can calm myself down when feeling angry \\
\hline 0.64 & 6. I know how to use good feelings to be creative in solving problems \\
\hline 0.51 & 26. I can make myself feel full of energy and motivated to do well in sports \\
\hline \multicolumn{2}{|r|}{ Factor 2: Identifying and understanding your own emotions } \\
\hline 0.61 & 4. I can tell what makes me feel good \\
\hline 0.51 & 11. When I feel unhappy, I can tell what has caused it \\
\hline 0.62 & 27. I can tell what makes me feel different emotions \\
\hline 0.50 & 1. I can tell when I feel unhappy or angry \\
\hline 0.50 & 9. I can tell when I am feeling happy \\
\hline 0.51 & 19. I can tell why my feelings change \\
\hline \multicolumn{2}{|r|}{ Factor 3: Dealing with emotions in others } \\
\hline 0.62 & 7. I know what makes other people feel happy \\
\hline 0.65 & 24. I know how to help another person calm down when he or she is feeling angry \\
\hline 0.57 & 15. I can tell what makes other people feel unhappy \\
\hline 0.61 & 23. I can tell why other person's feelings change \\
\hline 0.51 & 2. I know how to cheer someone up when they feel unhappy \\
\hline 0.59 & 13. I can tell when someone is feeling a pleasant emotion \\
\hline \multicolumn{2}{|r|}{ Factor 4: Perceiving emotion through facial expressions and body language } \\
\hline 0.63 & 25. I am able to tell what feelings I show on my face \\
\hline 0.60 & 21. I can tell what other people feel from the way their body changes \\
\hline 0.58 & 17. I can tell what I feel from the way my body behaves \\
\hline
\end{tabular}

Table 3. Reliability values of the Emotional Self-Efficacy Scale and its subscales

\begin{tabular}{|l|c|c|}
\hline Variables & Alpha & CR \\
\hline Emotional self-efficacy & 0.74 & 0.92 \\
\hline Manage emotions & 0.75 & 0.78 \\
\hline Awareness of feelings & 0.77 & 0.85 \\
\hline Interacting emotions with others & 0.77 & 0.89 \\
\hline Understanding emotions through face and body language & 0.77 & 0.79 \\
\hline
\end{tabular}


Also, to test the research hypothesis, the relationship between emotional self-efficacy and high-risk sexual behaviors with Pearson correlation coefficient was examined and the correlation coefficient was $-0.79(\mathrm{P}<.01)$.

\section{Discussion}

The results showed that the emotional self-efficacy scale has good validity and reliability and this scale can be used to measure the emotional self-efficacy of Iranian children, adolescents and students. Because the Adult Emotional Self-Efficacy Scale is not able to measure all aspects of emotional self-efficacy in the sample of children and adolescents, the Emotional Self-Efficacy Scale (Qualter et al., 2015) is a good alternative for apply in adolescents and students samples. This scale can be used to measure emotional self-efficacy in counseling, treatment, education and research situations.

Also, the results showed that there is a significant relationship between emotional self-efficacy and high-risk sexual behaviors of students. The correlation coefficient between emotional self-efficacy and high-risk sexual behaviors is negative and significant, which shows that with increasing emotional self-efficacy, high-risk sexual behaviors decrease. This result is consistent with the results of previous studies (Collazo, 2005; DiIorio et al., 2004; Santelli et al., 2004; Sionéan et al., 2002). The results of this study have applications for reducing high-risk sexual behaviors, especially interventions derived from social cognitive theory have been able to successfully demonstrate high-risk sexual behaviors in adults (DiClemente et al., 2004; Hennessy et al., 2013; Romer et al., 2009). Modeling through activities such as role-playing that help adolescents identify stimuli that trigger unsafe sexual behaviors and avoid cognitive exercise to increase self-confidence to reject unsafe sex (DiClemente et al., 2004).

Our results revealed that there is a significant relationship between emotional self-efficacy and high-risk sexual behaviors of students. As emotional self-efficacy increases, high-risk sexual behaviors decrease. Therefore, it is suggested to design and implement interventions to increase emotional self-efficacy based on social cognitive theory (Bandura et al., 2003).

In addition to the findings, the present study has some limitations. One of the most important of these limitations is the lack of proper cooperation of some students to complete the questionnaire due to high academic busyness and the use of self-report questionnaires to collect data. Conducting research on a sample of students in Bandar Abbas is also one of the important limitations of the present study that should be considered.

Declaration of Conflicting Interests: The author(s) declared no potential conflicts of interest with respect to the research, authorship, and/or publication of this article.

Funding: The authors received no financial support for the research, authorship, and/or publication of this article.

Acknowledgements: We are grateful to all the participants who have contributed to this study. 


\section{References}

Babore, A., Romello, C., Candelori, C., Paciello, M., \& Cerniglia, L. (2016). Depressive symptoms, self-esteem and perceived parent- child relationship in early adolescence. Frontiers in Psychology, 7, 982

Byrne, B. M. (2016). Structural equation modeling with Amos (3rd ed., pp. 94-99). New York, NY: Routledge.9. Campbell,

Bhupinder S, Rakhi U. Self-efficacy and well-being of adolescents. Journal of the Indian Academy of Applied Psychology.2009; 35(2):227-32.

Carlo, G., McGinley, M., Hayes, R., Bate horst, C., \& Wilkinson. (2007). Parenting styles or practices? Parenting, sympathy, andprosocial behaviors among adolescents. The Journal of Genetic Psychology, 168(2), $147-176$.

CDC. (2011). National Youth Risk Behavior Survey. Retrieved September 4, 2011, from the Centers for Disease Control and Prevention Youth Risk Behavior Surveillance website http://www.cdc.gov/healt hyyou th/ yrbs/questioner ire rationale.html.

Chan, S. M., \& Chan, K. W. (2013). Adolescents' susceptibility to peer pressure: Relations to parent-adolescent relationship and adolescents' emotional autonomy from parents. Youth \& Society, 45(2), 286-302. Https: //doi.org/10.1177/00441 18X11 417733.

DelPriore, D. J., Schlomer, G. L., \& Ellis, B. J. (2017). Impact of fathers on parental monitoring of daughters and their affiliation with sexually promiscuous peers: A genetically and environmentally Controlled sibling study. Developmental Psychology, 53(7), 1330-1343. Https //doi.org/10.1037/dev00 00327

Dimbuene, Z. T., \& Defo, B. K. (2011). Risky sexual Behaviour among unmarried young people in Cameroon: Another look at family environment. Journal of Biosocial Science, 43(2), 129-153. Https: //doi. org/10.1017/S0021932010000635.

Finzi-Dottan, R., Bilu, R., \& Golubchik, P. (2011). Aggression and conduct disorder in former Soviet Union immigrant adolescents: The role of parenting style and ego identity. Children and Youth Services Review, 33(6), 918-926

Fardis, M. (2007).Expression and regulation of emotion in romantic relationship.

Fosco, G. M., Stormshak, E. a., Dishion, T. J., \& winter, C. (2012). Family relationships and parental monitoring during middle school as predictors of early adolescent problem behavior. Quality of Life Research Journal of Clinical Child and Adolescent Psychology, 41(2),

Harrell, Z. A. T, Slane, J. D \& Klump, K. L, (2009). Predictors of alcohol problems in college women: The role of depressive symptoms disordered eating, and family history of alcoholism, Addictive Behaviors, Vol. 34, ( 3); pg. 252.

Holliday, S. B., Ewing, B. A., Storholm, E. D., Parast, L., \& D’Amico, E. J. (2017). Gender differences in the association between conduct disorder and risky sexual behavior. Journal of Adolescence, 56, 75-83.

Kline, R. B. (2015). Principles and practice of structural equation modeling (4th Ed.). New York, NY: The Guilford Press.

Kogan, S. M., Cho, J., Allen, K., Lei, M.-K., Beach, S. R. H., Gibbons, F. X., Brody, G. H. (2013). Avoiding adolescent pregnancy: A longitudinal analysis of African-American youth. Journal of Adolescent Health, 53(1), 14-20. Https: //doi.org/10.1016/j. jado health .2013.01.024.

Lippold, M. A., Davis, K. D., Lawson, K. M., \& McHale, S. M. (2016). Day-to-day consistency in positive 
parent-child interactions and youth well-being. Journal of Child and Family Studies, 25(12), 3584-3592. Https: //doi.org/10.1007/s1082 6-016-0502-x.

Lynne-Landsman, S. D., Graber, J. A., Nickols, T. R. \& Bovine, G. J. (2011). "Is Sensation Seeking a Stable Trait or Does it Change over Time?" Journal of youth and adolescence, 40 (1), 48-58

Norbury, A., Kurth-Nelson, Zeb. Winston, Joel S., Roiser, Jonathan P., Husain \& Masud. (2015). "Dopamine Regulates Approach-Avoidance in Human Sensation Seeking”. International Journal of Neuro psycho pharmacology. 18, 1-10

Pattanakul, D. (2011). Parental responses to toddler's negative emotions

Pittman, J. F., Kerpelman, J. L., Soto, J. B., \& Adler-Baeder, F. (2012). Identity exploration in the dating domain: The role of attachment dimensions and parenting practices. Journal of Adolescence. Https: //doi. org/10.1016/j. adolescents.2012.04.006.

Shek, D. T. L., \& Liang, L. Y. (2017). Psychosocial factors influencing individual well-being in Chinese adolescents in Hong Kong: A six-year longitudinal study. Applied Research in Quality of Life. Https: //doi. org/10.1007/s1148 2-017-9545-4.

Shneyderman, Y., \& Schwartz, S. J. (2012). Contextual and intrapersonal predictors of adolescent risky sexual behavior and outcomes. Health Education \& Behavior, 40(4), 400-414. Https: // doi.org/10.1177/10901 98112447800.

Voisin, D. R., Harty, J., Kim, D. H., Elsaesser, C., \& Takahashi, L. M. (2017). Assessing the relationship between parental influences and wellbeing among low income African American adolescents in Chicago. Child \& Youth Care Forum, 46(2), 223-242. Https: // doi.org/10.1007/s1056 6-016-9373-y.

Wang, Z., Vang, M., Lookadoo, K., Tchernev, J. M. \& Cooper, C. (2014). “Engaging High-Sensation Seekers: The Dynamic Interplay of Sensation Seeking, Message Visual-Auditory Complexity and Arousing Content". Journal of communication, 65, 101-124

Yucel, D., \& Yuan, A. S. V. (2016). Parents, siblings, or friends? Exploring life satisfaction among early adolescents. Applied Research in Quality of Life, 11(4), 1399-1423. Https: /Doi. org/10.1007/s1148 2-0159444-5. 